\title{
Une semaine dans la vie de camarades (1976) : manifeste cinématographique de la contre-culture québécoise
}

\section{Marc-André Robert}

Volume 67, numéro 2, automne 2013

URI : https://id.erudit.org/iderudit/1027647ar

DOI : https://doi.org/10.7202/1027647ar

Aller au sommaire du numéro

Éditeur(s)

Institut d'histoire de l'Amérique française

ISSN

0035-2357 (imprimé)

1492-1383 (numérique)

Découvrir la revue

Citer cet article

Robert, M.-A. (2013). Une semaine dans la vie de camarades (1976) : manifeste cinématographique de la contre-culture québécoise. Revue d'histoire de l'Amérique française, 67(2), 193-221. https://doi.org/10.7202/1027647ar
Résumé de l'article

En avril 1975 s'ouvre la Rencontre internationale de la contre-culture (RIC) de Montréal. Événement phare de la contre-culture québécoise, elle donne lieu à la production d'un long-métrage documentaire de quatre heures empruntant à l'esthétique du cinéma direct : Une semaine dans la vie de camarades (1976), des cinéastes Jean Gagné et Serge Gagné, deux acteurs de premier plan de la mouvance contre-culturelle au Québec. Portrait social et politique de la culture québécoise, ce film propose une série d'entrevues avec des « travailleurs culturels » à travers un voyage aux quatre coins du Québec. Critique de la culture institutionnalisée des années 1970, Une semaine dans la vie de camarades explore les différentes manifestations culturelles populaires en sol québécois. À partir d'une analyse historique des représentations de la contre-culture dans ce film, cet article vise à comprendre les composantes du discours politique associé à ce phénomène. En ressort la prédominance d'une prise de parole collective dans l'espace public. Manifeste à l'endroit des pouvoirs politique et économique, elle expose les clivages entre le peuple et les élites en regard à la culture.
Tous droits réservés @ Institut d’histoire de l’Amérique française, 2014

Ce document est protégé par la loi sur le droit d'auteur. L'utilisation des services d'Érudit (y compris la reproduction) est assujettie à sa politique d'utilisation que vous pouvez consulter en ligne.

https://apropos.erudit.org/fr/usagers/politique-dutilisation/ 


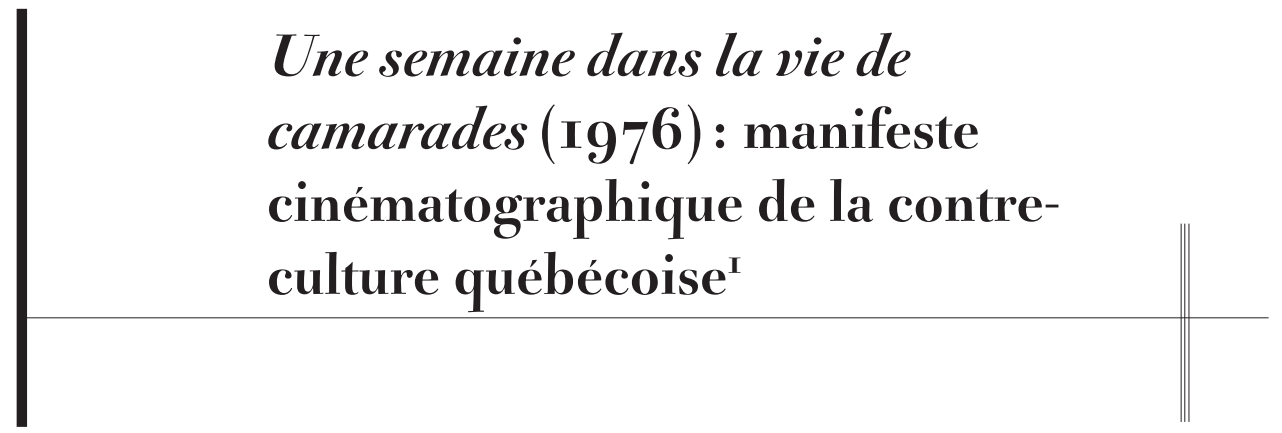

MARC-ANDRÉ ROBERT

Université Laval

RÉSUMÉ • En avril 1975 s'ouvre la Rencontre internationale de la contre-culture (RIC) de Montréal. Événement phare de la contre-culture québécoise, elle donne lieu à la production d'un long-métrage documentaire de quatre heures empruntant à l'esthétique du cinéma direct: Une semaine dans la vie de camarades (1976), des cinéastes Jean Gagné et Serge Gagné, deux acteurs de premier plan de la mouvance contre-culturelle au Québec. Portrait social et politique de la culture québécoise, ce film propose une série d'entrevues avec des «travailleurs culturels» à travers un voyage aux quatre coins du Québec. Critique de la culture institutionnalisée des années 1970, Une semaine dans la vie de camarades explore les différentes manifestations culturelles populaires en sol québécois. À partir d'une analyse historique des représentations de la contre-culture dans ce film, cet article vise à comprendre les composantes du discours politique associé à ce phénomène. En ressort la prédominance d'une prise de parole collective dans l'espace public. Manifeste à l'endroit des pouvoirs politique et économique, elle expose les clivages entre le peuple et les élites en regard à la culture.

Abstract • The Rencontre internationale de la contre-culture (RIC) opened in Montréal in April 1975. As the key event of Quebec's counterculture phenomenon, it led to the production of a four-hour feature documentary modeled on the aesthetics of direct cinema, Une semaine dans la vie de camarades (1976), by filmmakers Jean Gagné and Serge Gagné,

1. Je tiens d'abord à remercier le Fonds québécois de recherche sur la société et la culture (FQRSC) pour le soutien financier à mes recherches doctorales ayant permis la réalisation de cet article, ainsi que Jean Gagné et Serge Gagné pour leur générosité, leur intérêt pour le projet, de même que pour les entretiens qu'ils m’ont accordés. Je tiens à remercier également Karim Larose et Frédéric Rondeau pour leur évaluation respective, leurs commentaires et suggestions ayant mené à la production de cet article, de même qu'aux évaluateurs anonymes ayant accepté de jeter un œil critique sur ce travail. 
two leading figures in the countercultural movement in Quebec. A social and political portrait of Quebec's culture, this film proposed a series of interviews with "cultural workers" across Quebec. Une semaine dans la vie de camarades was a solid plea against the institutionalized culture of the 1970s and explored various manifestations of popular cultural in Quebec. From an historical analysis of the representations of counterculture in the documentary, this article aims to understand the main aspects of the political discourse associated with this phenomenon. The results show the predominance of a collective voice in the public space. As a manifest directed at both the political and economical powers, this voice showed the cultural rupture between the people and the elites.

Puisse chacun être son propre historien ${ }^{2}$

$\mathbf{E}$ n avril 1975 s'ouvrait la Rencontre internationale de la contre-culture (RIC) de Montréal, logée à la salle Saint-Sulpice de la Bibliothèque nationale (du 21 au 26 avril) puis au Palais du commerce (27 avril). Événement organisé conjointement par l'Atelier d'expression multidisciplinaire (ATEM) et le collectif de la RIC, sous la direction de Jocelyn Pagés, ce colloque ouvert au public avait pour objectif premier, en donnant la place et une tribune à celles et ceux qui s'en réclamaient, de proposer un débat public sur la question de la culture au Québec, débat à travers lequel "pourrait se dire la vie quotidienne et sociale des québécois $[s i c]^{4}$.»

Tout au long de cette semaine, nombreux sont les artistes, écrivains, poètes, chanteurs, musiciens, cinéastes, militants marxistes, qui convergent à la Rencontre internationale, qui deviendra un véritable lieu de mémoire de la contre-culture québécoise. S'y côtoient entre autres l'intellectuel Patrick Straram dit «le Bison ravi»; le cinéaste Gilles Groulx; les poètes Josée Yvon, Denis Vanier, Charles Plymell et Allen Ginsberg; les chanteurs Lucien Francœur, Raoul Duguay et Plume Latraverse; l'écrivain William Burroughs; et l'artiste Baron Philip. À l'aune de mai 68 en France et du mouvement hippie américain des années 1960, la contre-culture québécoise trouve, dans cet événement, un cadre temporel et spatial permettant à ses principaux acteurs et actrices une prise de parole libre et collective dans l'espace public, lieu de toutes les revendications. Un esprit contre-

2. Jean-Luc Godard et Jean-Pierre Gorin, Tout va bien [film], Anouchka Films, 1972, 95 min.

3. Faisaient aussi partie du collectif de la Rencontre internationale de la contre-culture Marc Desjardins, Hélène René et Réjean Bergeron.

4. Édouard Apanaszewski, "Rencontre internationale "de la contre-culture" ", Courrier Sud (5 mai $1975): 8$. 
culturel s'y déploie donc, à travers une démarche de revendication à la fois politique et sociale qui corrobore le projet sociétaire soutenu par les acteurs du phénomène, soit, selon le politologue Gaétan Rochon, la création d'une "Cité nouvelle» qui se veut «la continuation de la politique [mais] par d'autres moyens ${ }^{5} »$.

"[F]igures quasi mythiques ${ }^{6}$ » de la contre-culture en terre québécoise, les frères Jean et Serge Gagné, cinéastes marginaux et indépendants à qui l'on doit plusieurs films-essais méconnus d'une richesse historique surprenante $^{7}$, sont parmi les membres et fondateurs du Centre d'essai Le Conventum et de l'ATEM, structure d'accueil de la Rencontre internationale de 1975. S'étant vu confier la responsabilité de la captation filmique de la RIC pour l'ATEM ${ }^{8}$, ils développent un projet de long métrage s'appuyant en partie sur les images captées pour l'occasion et portant, plus globalement, sur l'idéologie de la contre-culture au Québec. J’y reviendrai.

Le projet, achevé en 1976, s'intitule Une semaine dans la vie de camarades ${ }^{9}$, un film-fleuve (quatre heures!) à la confluence des genres, mêlant fiction, documentaire et cinéma direct, dans une improvisation cinématographique que l'on reconnaît à la filmographie des frères Gagné, celle des films-collage. Dans une perspective historique, ce film constitue un document sociologique et ethnographique d'importance. Produit par des contre-culturistes qui y critiquent, dans une approche bien singulière, la culture (avec un grand «C») québécoise institutionnalisée des années 1970, Une semaine dans la vie de camarades renseigne à la fois sur l'esprit révolu-

5. Gaétan Rochon, Politique et contre-culture (Montréal, Hurtubise HMH, coll. «Cahiers du Québec - Science politique», 1979), 43.

6. Isabelle Morrissette, "Vous êtes pas tannés de mourir bande de caves”. Bref survol du cinéma québécois de la contre-culture ", À rayons ouverts, 86 (2011): 22.

7. Notamment La marche à l'amour (1996), documentaire sur le poète Gaston Miron; Étrange histoire (1998), autre documentaire sur un poète, Gilbert Langevin; de même que Un souffle qui brûle (2002) sur le sculpteur Armand Vaillancourt.

8. Les responsables de la RIC souhaitaient une diffusion publique de l'événement, mais redoutaient qu'elle fasse l'objet d'une récupération, en aval. C'est pourquoi ils opéraient une certaine sélection quant aux droits de captation. Radio-Canada avait notamment dépêché un réalisateur sur place, Gérard Binette, pour pouvoir diffuser, chaque jour, un compte rendu de la Rencontre. Serge Gagné se souvient également avoir vu quotidiennement Minou Petrowski, journaliste et animatrice à Radio-Canada. Les photographes Bertrand Carrière et Errol Gagné ont aussi couvert l'événement pour l'ATEM. Jean Gagné et son équipe étaient donc parmi les quelques privilégiés chargés de filmer la RIC. Or, puisque la captation se faisait sur pellicule $16 \mathrm{~mm}$, il lui était impossible d'assurer le tournage intégral de l'événement. «Nous devions choisir sur le motif particulièrement lors des rencontres-colloques et en soirée lors de spectacles de musique. Pour ce qui a été de la journée au Palais du Commerce, là nous avons pas mal tout filmé.» Entrevue et échanges courriel avec Jean Gagné et Serge Gagné, le 28 octobre 2012 et 6 novembre 2012.

9. Jean Gagné et Serge Gagné, Une semaine dans la vie de camarades, Productions 89/ACPAV, 1976, $240 \mathrm{~min}$. 
tionnaire de la contre-culture ainsi que sur l'esthétique cinématographique propre à cette mouvance.

Encore faut-il s'entendre sur une définition opératoire de la "contreculture», de même que sur une périodisation effective. En entrevue avec le sociologue Jean-Philippe Warren, le professeur en littérature et directeur du Centre d'archives Gaston-Miron sur la culture et la littérature québécoise Karim Larose avance que

la contre-culture agit comme un creuset dans lequel se croisent des tendances diverses réunies par la conviction que le monde doit tendre vers la créativité, un élargissement de la conscience, le pluralisme, l'affirmation d'une éthique écologique, la solidarité humaine et la recherche de nouvelle façon — non réprimées — de percevoir le monde. [...] [Mais aussi] le désir de créer un réseau d'information parallèle, un autre mode de circulation des nouvelles et, tout aussi bien, des œuvres d'art, est sans aucun doute l'un des éléments les plus intéressants du mouvement contre-culturel québécois - et l'un de ses crédos. [...] Cela dit, la contre-culture se définit avant tout en tant que pôle d'opposition à la culture officielle ${ }^{10}$.

C'est justement cet esprit de conviction collective et ce désir de création d'un réseau d'information parallèle qui permet de saisir la contre-culture (québécoise) comme discours politique, comme idéologie. À l'origine du terme, l'historien américain Theodore Roszak explique dès 1968 l'origine de la contre-culture par «l'effervescence contestataire, à la fois sociale, politique et culturelle, d'une partie de la jeunesse américaine des années 1960. [...] La révolte des "enfants de la technocratie" contre une société du contrôle rationnel qui, toujours plus étendue, "orchestre tout le contexte humain" ${ }^{\prime 1} \ldots$..."

Cette définition d'un esprit contestataire à l'égard du pouvoir, fut-il politique, économique ou autre, est également au cœur de la contre-culture pour Dimitry Anastakis, à l'origine du collectif The Sixties: Passion, Politics and Style: "The counterculture, Vietnam, civil rights, and so many other movements and events [expressed throughout the Sixties] were sparked by a passion for challenging preconceived notions and traditional approaches to politics, art, and protest ${ }^{12}$.» Au surplus, si l'on accepte une telle «intention politique», nommons-la ainsi, au cœur de la contre-culture, elle s'en voit

10. Jean-Philippe Warren et Karim Larose, "Terra incognita ", dans Olivier Kemeid et Jean-Philippe Warren, dir., «Dossier: la contre-culture dans le Québec inc. », Liberté, 299 (2013): 15-16.

11. Olivier Penot-Lacassagne, "Qu'est-ce qu'une contre-culture», dans Christophe Bourseiller et Olivier Penot-Lacassagne, dir., Contre-cultures ! (Paris, CNRS Éditions, 2013), p. 5.

12. Dimitri Anastakis, "Introduction», dans Dimitri Anastakis, dir., The Sixties: Passion, Politics and Style (Montréal/Toronto, McGill-Queen’s University Press, 2008), p. 9. 
inévitablement renforcée par son expression à l'intérieur même du pouvoir qu'elle dénonce: "counterculture is best defined not as an alternate system of social interactions and ideologies existing outside the expected, dominant culture but rather as the shifting sets of responses, refusals, and acceptances performed by actors in the cultural process ${ }^{13}$.» Une étude de la contreculture des années 1960 et 1970 ne peut faire abstraction, souligne Frédérick, de la superposition du culturel et du politique : «le politique devint culturel $[\ldots]$ et le culturel se politisa à une vitesse fulgurante ${ }^{14}$ ».

La contre-culture en situation québécoise s'inspire et s'alimente de cet esprit contestataire de la jeunesse américaine des années $1960^{15}$. Les objectifs et les projets diffèrent, mais l'essentiel demeure. Que ce soit à travers les tensions linguistiques comme l'Opération McGill en 1968 et les manifestations contre le Bill 63 du gouvernement de Jean-Jacques Bertrand, rappelle l'historien Sean Mills ${ }^{16}$, ou encore la création de la revue Mainmise, dans laquelle on dénonçait, entre autres, le contrôle de l'information par certains privilégiés ayant pour conséquence un détournement de la démocratie $^{17}$, l'investissement de l'espace public au nom de la culture plurielle retentit également au Québec.

Les principaux acteurs québécois de la contre-culture utilisent le concept de "mouvance» pour la désigner. Ce concept a une signification particulière. Il n'est certes pas, aux yeux de ceux-ci, synonyme de «mouvement». Alors qu'un mouvement suppose à la fois organisation et planification - aussi minimalistes qu'elles puissent être - , dispose d'un objectif sinon d'un but à atteindre; une mouvance possède un caractère moins stable, moins formel et plus changeant, fluctuant. Certains tenants de la contre-culture québécoise préfèrent cette dénomination, un peu impressionniste certes, mais fidèle à un certain registre de l'impulsion et de la réaction spontanée ${ }^{18}$. Tant et si bien qu'il serait plus juste de parler

13. Stuart Henderson, Making the Scene: Yorkville and Hip Toronto in the 1960's (Toronto, University of Toronto Press, 2011), p. 5. Souligné dans le texte.

14. Frédéric Robert, «Introduction», dans Frédéric Robert, dir., Contre-culture dans l'Amérique des années 60 (Paris, Michel Houdiard Éditeur, 2012), p. 3.

15. J.-P. Warren et K. Larose, loc. cit., 14.

16. Sean Mills, «La langue de la libération», dans Michèle Thériault, dir., Des actions parlantes : aspects de la culture québécoise des années 1960 et 1970 (Montréal, Galerie Leonard \& Bina Ellen, 2012), p. 13-52.

17. Marie-France Moore, "Mainmise, version québécoise de la contre-culture », Recherches sociographiques, 14, 3 (1973): 369-371.

18. Le chanteur et professeur de littérature Lucien Francœur, artiste de la contre-culture québécoise, adopte ce vocable au cours d'une table ronde radiophonique sur la contre-culture sur les ondes de la Première Chaîne de Radio-Canada, à l'occasion du lancement de l'exposition «La contre-culture : manifestes et manifestations» organisée par Bibliothèque et Archives nationales du Québec en 2011. Voir «La contre-culture: manifestes et manifestations ", Je l'ai vu à la radio, 6 août 2011, 15h16, www.radio-canada. 
de la mouvance des «contre culturiste ${ }^{19}{ }^{1}$. Le sociologue Jules Duchastel parle plutôt, pour sa part, d'une «tendance idéologique contre-culturelle $^{20}$ », soulignant le pluralisme de la démarche.

Quant à la périodisation du phénomène, plusieurs experts postulent sur son émergence, sans toutefois définir clairement le moment de la fin (y en a-t-il un?). Certains situent son avènement au moment de la Nuit de la poésie de mars 1970 au Gésu à Montréal ${ }^{21}$. D’autres retiennent la publication du premier numéro de la revue Mainmise en octobre $1970^{22}$, ou encore la présentation de l'Osstidcho en $1968^{23}$. Karim Larose évoque même les élections provinciales d'avril 1970 en raison de la participation du Parti poétik, dont on ne sait que peu de $\operatorname{choses}^{24}$. Simon-Pier LabelleHogue préfère la désigner en tant que "continuum " plus ou moins diffus depuis les années 1940 (avec Refus global notamment) ${ }^{25}$. À travers son documentaire La République des beaux-arts (1997), Claude Laflamme suggère l'année 1968 en raison de l'intensité des mouvements de revendication étudiants. Ces divers postulats se valent certainement tous. Me gardant de proposer une date précise quant aux débuts (et à la fin) du phénomène, je note que les chercheurs et experts s'entendent à peu près tous pour le situer à cheval sur la décennie 1970 .

Une semaine dans la vie de camarades mérite une étude substantielle surtout parce qu'il se range parmi les seuls longs métrages «documentaires ${ }^{26}$ » ayant pour thème principal la contre-culture en situation québécoise, mais aussi et surtout puisqu'il est le produit contemporain de cette époque. Certes, les cinéastes Jean-Claude Labrecque et Jean-Pierre Masse ont

ca / audio-video/pop.shtml\#urlMedia=http :/ / www.radio-canada.ca/ Medianet $/ 2011 / \mathrm{CBF} /$ JeLaiVuALaRadio201108061505_1.asx [consulté le 10 octobre 2012].

19. L'expression est employée notamment par l'écrivain et professeur de littérature Robert Barberis. Robert Barberis, «Les contre-culturistes », Le Jour, 26 avril 1975, 13.

20. Jules Duchastel, «La contre-culture, une idéologie de l'apolitisme», dans La transformation du pouvoir au Québec: actes du colloque de l'ACSALF (1979) (Montréal, Éditions Albert Saint-Martin, 1979), p. 257.

21. Guildo Rousseau, «Les relations littéraires Québec/États-Unis au XIX siècle», dans Claude Savary, dir., Les rapports culturels entre le Québec et les États-Unis (Québec, IQRC, 1984), p. 74-75; Jean-Claude Labrecque et Jean-Pierre Masse (réal. et scén.), La Nuit de la poésie de mars 1970 [documentaire], Office national du film du Canada, 1971, $111 \mathrm{~min}$.

22. Marie-France Moore, «Mainmise : version québécoise de la contre-culture», Recherches sociographiques, 14, 3, (1973): 364-365.

23. Michel Biron, François Dumont et Élisabeth Nardout-Lafarge, Histoire de la littérature québécoise (Montréal, Boréal, 2010), p. 486.

24. J.-P. Warren et K. Larose, loc. cit., 16.

25. Simon-Pier Labelle-Hogue, «La contre-culture québécoise par la méthode, lieux de distinction », dans Christophe Bourseiller et Olivier Penot-Lacassagne, dir., op. cit., 147.

26. Inspiré du genre documentaire, ce film est toutefois à la confluence de plusieurs genres. J'aurai l'occasion d'y revenir. 
également réalisé un documentaire contemporain sur le sujet, mais concentré surtout autour d'un événement, La Nuit de la poésie de mars $1970^{27}$. Je l'évoquais à l'instant, en 1997, La République des beaux-arts (la malédiction de la momie) de Claude Laflamme, un documentaire sur l'occupation de l'École des beaux-arts de Montréal par ses étudiants, en octobre $1968^{28}$, explore également le phénomène contre-culturel, mais $a$ posteriori. Une semaine dans la vie de camarades se veut ainsi un témoignage authentique, unique et contemporain des enjeux soulevés par les tenants de la contre-culture québécoise.

Exploitant les images qu'ils ont captées pour l'occasion, les frères Gagné mettent en scène la Rencontre internationale de la contre-culture, qu'ils articulent comme trame narrative de leur film. Ce qui en fait une pièce d'archive à part entière. D'autant plus que la RIC est considérée par plusieurs comme le point culminant de la contre-culture au Québec et précède, rappelons-le, l'élection du Parti québécois de René Lévesque en 1976, événement qui provoque un changement de paradigme dans l'environnement politique québécois de même qu’au sein du milieu cinématographique. Yves Lever souligne que «[1]'espoir de voir surgir un nouveau cinéma national renait, d'autant plus que les dirigeants politiques héritent d'une toute nouvelle loi du cinéma (votée le 19 juin 1975) que leurs prédécesseurs n'ont pas eu le temps de mettre en application ${ }^{29}$ ».

En plus de la trace historique qu'il représente, Une semaine dans la vie de camarades est également réalisé et produit par deux acteurs de premier plan de la mouvance. À cette époque, Jean et Serge Gagné sont de tous les événements, instigateurs mêmes de certains d'entre eux; ils côtoient les principaux acteurs avec qui ils entretiennent des amitiés parfois ponctuelles, parfois de longue date. Ce film permet ainsi, en parallèle, de comprendre l'articulation d'une esthétique cinématographique propre à la contre-culture.

Enfin, Une semaine dans la vie de camarades n'a pas connu de diffusion publique dans le circuit commercial. Il ne fut pas distribué dans les salles de cinéma, sinon dans quelques salles parallèles. Partageant surtout leur film au sein de cercles d'artistes contre-culturels, les réalisateurs ne cachent pas d'ailleurs leur volonté d'agir et d'exister artistiquement à l'extérieur des réseaux convenus. Le public cible se trouve ainsi en adé-

27. J.-C. Labrecque et J.-P. Masse (réal. et scén.), op. cit.

28. Pendant cinq semaines, les étudiants hissent le drapeau noir de la République des beaux-arts et provoquent un débat de fond sur le rôle de l'art et de l'artiste dans la société. Claude Laflamme, $\mathrm{La}$ République des beaux-arts [film], Cinéma libre, Montréal, 1997, 75 min.

29. Yves Lever, Histoire générale du cinéma au Québec (Montréal, Boréal, 1995, 2édition), p. 243. 
quation avec la démarche et l'esprit du projet. De telles caractéristiques uniques justifient une étude lui étant entièrement consacrée.

Par ailleurs, l'historiographie de la contre-culture ne contient que très peu d'études de cas touchant spécifiquement à son legs cinématographique, c'est-à-dire aux films marginaux réalisés et produits par les acteurs eux-mêmes. Les synthèses en histoire du cinéma contiennent évidemment quelques encarts sur la période, sans réellement creuser les exemples ${ }^{30}$. Prenant appui sur les travaux du sociologue Jules Duchastel ${ }^{31}$, de même que sur l'ouvrage du politologue Gaétan Rochon ${ }^{32}$ sur la dimension (a politique de l'idéologie contre-culturelle, il m'apparaît pertinent d'interroger le film des frères Gagné justement sous cet angle. Surtout puisqu'il représente une certaine forme de manifeste politique du phénomène. Il s'agit là, dans un acte de mise en mémoire, d'une prise de parole inédite d'acteurs ayant vécu la contre-culture «de l'intérieur» et non celle d'observateurs externes. Pour reprendre les mots de l'historien Marc Ferro, un tel film incarne une "contre-analyse de la société», ici contreculturelle $^{33}$, permettant de comprendre l'esprit révolutionnaire à la source du phénomène. Une semaine dans la vie de camarades est donc susceptible de renseigner, d'une façon originale, sur la prégnance du discours (a) politique suggéré par Duchastel et Rochon.

Dans cet article, je tâche ainsi d'analyser les représentations politiques (plus particulièrement l'interprétation des notions de pouvoirs politique et économique) et sociales (classes et mouvements sociaux) de la mouvance contre-culturelle québécoise dans le film Une semaine dans la vie de camarades. Il s'agit ainsi de mesurer en quoi l'anti-impérialisme, l'antitechnocratie et la revendication d'une pluralité culturelle populaire non institutionnalisée trouvent écho dans le discours des acteurs de la contre-culture. Il ressort de cette analyse une prémisse selon laquelle la contre-culture s'incarne en tant que "contre-pouvoir", suivant l'expression des philosophes Miguel Benasayag et Diego Sztulwark ${ }^{34}$, dans un but d'émancipation collective. Ce rejet du pouvoir dénonce ici spécifiquement l'institutionnalisation et l'homogénéisation de la culture par l'État au profit de l'économie et du culte de la rationalité.

30. Notamment Michel Coulombe et Marcel Jean, dir., Le dictionnaire du cinéma québécois, nouvelle édition revue et augmentée par Michel Coulombe (Montréal, Boréal, 2006), 821 p.

31. J. Duchastel, loc. cit., 253-264.

32. Gaétan Rochain, Politique et contre-culture (Montréal, Hurtubise HMH, 1979), 211 p.

33. Marc Ferro, Cinéma et histoire, nouvelle édition refondue (Paris, Gallimard, 1993), p. 32-40.

34. Voir Miguel Benasayag et Diego Sztulwark, Du contre-pouvoir (Paris, La Découverte, 2003). 
La méthode s'inspire de l'analyse historique de la source cinématographique développée surtout par les historiens français Marc Ferro ${ }^{35}$ et Pierre Sorlin ${ }^{36}$ dans les années 1970, puis plus récemment par Michèle Lagny $^{37}$ et Antoine de Baecque ${ }^{38}$. Une retranscription intégrale, scène par scène, colligeant dialogues, détails des plans, trame sonore et description scénique sert de matériel de base. Chacune des scènes est ensuite associée à un ou plusieurs thèmes qu'elle représente. L'association des scènes entre elles permet une analyse de la prégnance des thèmes dans l'œuvre, thèmes auxquels on associe le contexte historique, politique, économique, social et culturel de production. La résultante génère un portrait signifiant des multiples représentations émanant du film.

J'examine, dans un premier temps, le contexte de production et de réalisation d'Une semaine dans la vie de camarades (sa structure, son synopsis et sa distribution) dans le but de situer l'œuvre au cœur d'une démarche contre-culturelle cinématographique qui se veut, en elle-même, revendicatrice d'une forme de contre-pouvoir dirigé à l'endroit de l'industrie cinématographique. Dans un deuxième temps, je montre en quoi les caractéristiques de la contre-culture, telles que représentées dans le film, démontrent une prise de parole de laquelle émerge une dénonciation du pouvoir politique, celui de l'État, et économique, celui du capital. Ces caractéristiques se rapportent, entre autres, aux concepts de travailleurs culturels, d'identité et de liberté (individuelle et collective), que je passe en revue successivement.

\section{UNE DÉMARCHE CINÉMATOGRAPHIQUE «CONTRE-INSTITUTIONNELLE »}

Faut que ça se fasse, affirme Edgar à son ami Jean-Gauguet Larouche ${ }^{39}$. Pour réparer nos gaffes. [...] Prendre trois semaines, un mois. Faire cette tournée-là. Les trois années, on a vu pas mal ce qui s'était passé à Montréal, les gars qui étaient importants. Mais c'est pas plus représentatif que tout ça. Allons voir ailleurs ${ }^{40}$.

36. Pierre Sorlin, Sociologie du cinéma : ouverture pour l'histoire de demain (Paris, Aubier Montaigne, 1992, $2^{\mathrm{e}}$ édition), $319 \mathrm{p}$.

37. Michèle Lagny, De l'histoire du cinéma : méthode historique et histoire du cinéma (Paris, Armand Colin, 1997), 298 p.

38. Antoine de Baecque, Histoire et cinéma (Paris, Cahiers du cinéma, 2008), 96 p.

39. Sculpteur et poète, Jean-Gauguet Larouche est l'un des responsables du projet Le Conventum et membre du Conseil d'administration de l'Association des sculpteurs du Québec.

40. Régis Painchaud cité dans Jean Gagné et Serge Gagné, op. cit., 106 min à 108 min. 
Ces quelques phrases tirées du film décrivent parfaitement bien le synopsis d'Une semaine dans la vie de camarades. Edgar Azède Plamondon ${ }^{41}$, jeune trentenaire, entreprend une visite du Québec afin de sonder différents acteurs des milieux culturels régionaux et recueillir leurs perceptions quant à la situation de la culture en ce milieu des années 1970. La narration de ce dernier constitue la seule dimension fictive du film. Pour le reste, on navigue surtout dans les eaux du genre documentaire. Plus exactement encore dans celles du cinéma direct, un genre popularisé, au Québec et en France notamment, dans les années 1950 et 1960. Pour la suite du monde (1963) de Pierre Perrault, Michel Brault et Marcel Carrière, célèbre documentaire sur la pêche aux marsouins à L'Isle-aux-Coudres, œuvre pionnière du genre au Québec, en est aussi l'emblème. En octobre 1963, soit quelques mois après l'adoption officielle du terme «cinéma direct» par le MIPE-TV de Lyon ${ }^{42}$, le clerc Henri-Paul Sénécal, collaborateur à la revue Séquences, résumait admirablement bien l'essence de ce courant. L'essence du cinéma direct (ou cinéma-vérité, du côté anglais), c'est

la reproduction la plus fidèle possible d'une réalité «vivante et saignante». C'est celui du constat brut d'une réalité sociale ou psychologique. Le cinéaste doit être le témoin impartial de la réalité. Son rapporteur impassible. Il doit confier au hasard de l'enregistrement le soin de "capter les plus secrets, peut-être le plus insaisissable d'un être» dans ses moments privilégiés d'abandon. La spontanéité et le naturel de l'interprétation de personnages réels vivant des événements ou des drames réels forment les éléments de base du cinéma-véritét ${ }^{43}$.

Une définition qui, d'ailleurs, rejoint celle, plus récente, de Gilles Marsolais pour qui, le cinéma direct

désigne un nouveau type de cinéma documentaire qui, au moyen d'un matériel de prise de vues et de son synchrone, autonome, silencieux, léger, mobile et aisément maniable, de format $16 \mathrm{~mm}$, tente de cerner «sur le terrain» la parole et le geste de l'homme en action, placé dans un contexte naturel, ainsi que l'événement au moment même où il se produit. Il s'agit d'un cinéma qui tente de coller le plus possible aux situations observées, allant même jusqu’à

41. Le surnom "Azède» (lire AZ) découle d'une démarche lettriste que l'on retrouve fréquemment dans l'œuvre des frères Gagné, notamment dans le film L'ou 'L (1973). Entrevue avec Serge Gagné, 28 octobre 2012.

42. Séverine Graff, "Unions et désunions autour du "cinéma-vérité" : le MIPE-TV 1963 de Lyon ", 1895 : revue d'histoire du cinéma, 64 (automne 2011).

43. Henri-Paul Sénécal, "Qu’est-ce que le cinéma vérité?», Séquences : la revue de cinéma, 34 (octobre 1963): 5 . 
y participer, et de restituer honnêtement à l'écran la «réalité» des gens et des phénomènes ainsi approchés ${ }^{44}$.

Armé seulement de sa caméra, le cinéaste part ainsi à la rencontre du réel, sans scénario si ce n'est que la problématique qui l'intéresse, mais surtout sans idée préconçue. Une semaine dans la vie de camarades respecte sensiblement la formule, à l'exception de la présence d'un personnage principal.

Or Edgar, tout effacé qu'il est au profit des gens qu'il rencontre, n'est au fond qu'un agent liant. Il aurait d'ailleurs très bien pu ne pas figurer dans le film sans qu'il n'y ait de véritable accroc au "récit». Mais cette confusion des genres est aussi ce qui caractérise le cinéma des frères Gagné. On se trouve ainsi dans une sorte de fiction documentaire, cela dit plus près du documentaire que de la fiction. On relève aussi cet intérêt pour la confusion des genres chez d'autres cinéastes, tenants de la contreculture, comme Gilles Groulx ${ }^{45}$. Dans une entrevue qu'il accorde en 1978 au rédacteur en chef de la revue Séquences, Léo Bonneville, Groulx confirme que ce qui

[1]'intéresse au cinéma, c'est l'incontestabilité. Je tiens à ce que le spectateur ne puisse dire: voici une situation de fiction qui n'a aucun rapport avec la réalité et, qu'il ne puisse pas dire à l'égard du documentaire : voici un documentaire tout à fait contestable. [...] Au fond, je cherche à rendre les films que je fais incontestables, quel que soit le moyen employé. Je veux abolir la séparation des genres ${ }^{46}$.

"Film-collage», comme se plaît à le qualifier Serge Gagné ${ }^{47}$, Une semaine dans la vie de camarades rompt également avec la linéarité habituelle du scénario. Avec la Rencontre internationale de la contre-culture de Montréal comme trame de fond, le film se divise en sept parties, correspondant aux sept jours que dura l'événement, précédé d'une introduction. Chaque partie commence par des extraits de conférences, ateliers ou prestations musicales de personnalités ayant pris part à la RIC. Après quoi le périple d'Edgar se poursuit à travers les régions du Québec.

Il faut préciser cependant que le choix d'extraits de la RIC ne participe pas à construire ou à alimenter la trame narrative du récit. Ils ont été sélectionnés par souci de représentation de l'ensemble des activités et

44. Gilles Marsolais, «Cinéma direct», dans M. Coulombe et M. Jean, dir., op. cit., 140.

45. Isabelle Morrissette, loc. cit.

46. Gilles Groulx cité dans Léo Bonneville, «Entretien avec Gilles Groulx. Ce qui m’intéresse au cinéma, c'est l'incontestabilité", Séquences: la revue de cinéma, 92 (1978): 9.

47. Entrevue avec Serge Gagné, 28 octobre 2012. 
discussions de chacune des journées, certains moments jugés plus forts et porteurs que d'autres. D’où l'impression de «collage» que Serge Gagné mentionnait lors d'un entretien récent et que l'on retrouve dans la description qu’en fait Yves Rousseau: «Entrevues, spectacles, fiction, poésie, road movie, histoire et anarchie se fondent dans cette comédie humaine éclatée ${ }^{48}$."

Le style cinématographique singulier, tout comme le scénario et le choix du montage, n'est pas étranger au contexte de production et de réalisation d'Une semaine dans la vie de camarades. La démarche globale des frères Gagné se veut le reflet d'une volonté affirmée de demeurer à l'écart du système et de l'industrie, de certaines règles et carcans qui posent des entraves à la création et à l'imaginaire ${ }^{49}$. Faire du cinéma le plus librement possible afin de permettre pleinement, selon Serge Gagné, «la folie de faire se rencontrer deux fantômes qui ne se connaissent pas: le spectateur et le réalisateur ${ }^{50}$ ». C'est d'ailleurs pour cette raison qu'ils produisent eux-mêmes leurs films. Que ce soit par l'entremise de Productions $89^{51}$ pour Une semaine dans la vie de camarades, ou encore, aujourd'hui, avec Production Cocagne, Jean et Serge Gagné tiennent à l'entière indépendance de la production pour éviter les contraintes et assumer pleinement leur liberté créative. Dans Une semaine dans la vie de camarades, le générique d'ouverture rapporte également un crédit de production attribué à l'Association coopérative de productions audiovisuelles (ACPAV). Mais comme le précise l'historien du cinéma Yves Lever, créée en 1971, l'ACPAV

a fourni et fournit encore à une nouvelle génération de cinéastes l'occasion de faire leurs débuts, et même, pour certains, presque toutes leurs réalisations jusqu'à présent. Comme c'était le cas pour la génération de Groulx, de Carle et de Perrault, une vision du cinéma, une esthétique et une série de thèmes les unissent. [...] Refusant toute concession au commerce, la plupart ne cherchent pas vraiment à s'insérer dans les structures d'exploitation habituelles ${ }^{52}$.

48. Y. Rousseau, loc. cit., 283.

49. En entrevue, Serge Gagné mentionnait notamment comment le financement des grands organismes subventionnaires, tels que Téléfilm Canada et la Société de développement des entreprises culturelles (SODEQ), limitait, selon lui, la liberté créatrice du cinéaste en imposant des règles et une reddition de comptes serrée, de même qu'en privilégiant certains types de films plus conventionnels.

50. Entrevue avec Serge Gagné, 28 octobre 2012.

51. Les Productions 89 deviendra Production quatre vins neufs, puis Production Cocagne. Le nombre 89 fait référence à «l'an du péril », 1989. Le groupe à l'origine du Centre d'essai Le Conventum, dont Jean et Serge Gagné font partie, se désigne d'abord sous les noms de Québec 89 (titre d'une chanson d'André Duchesne), Atelier 89 et Empérillaid. Voir Louise Nantel, «Centre d'essai Le conventum: une tentative de décloisonnement", Jeu: revue de théâtre, 12 (1979): 124.

52. Y. Lever, op. cit., 324. 
On y retrouve des figures connues de la contre-culture cinématographique comme Pierre Harel, Jean Chabot, Brigitte Sauriol, Jean-Guy Noël, André Théberge et Alain Chartrand. En marge de l'industrie, l'ACPAV offre une «structure de production souple et conforme à leur démarche créatrice en plus de mettre en commun outils et expertise ${ }^{53}$ », ce qui permet aux frères Gagné de conserver la mainmise sur la réalisation. Marc Daigle, producteur à l'ACPAV, leur a notamment fourni une aide considérable pour financer la postproduction.

Une semaine dans la vie de camarades est produit avec un maigre budget de 15000 \$, obtenu grâce à une bourse du Conseil des arts du Canada qu'obtient Jean Gagné en 1975. Cela dit, ladite bourse ne lui est pas remise pour la production spécifique de ce film. Les deux cinéastes tirent profit du programme d'aide au cinéma artisanal de l'Office national du film (ONF) qui leur fournit, et ce n'est pas rien, la pellicule requise pour le tournage et divers services à l'étape de la production et de la postproduction: développement, caméra, lentilles, trépieds, éclairage, technicien éclairagiste (Guy Rémillard) et mixage (Jean-Pierre Joutelle et Michel Descombes).

Ils entreprennent ainsi leur tournée du Québec avec leur équipe technique (ils sont une dizaine) à bord du camion de type Ford Econoline que l'on retrouve dans le film (c'est le véhicule d'Edgar). Jean se charge de la réalisation, il en est le grand architecte, tandis que Serge occupe le rôle d'assistant à la réalisation et à la caméra. D'autres collaborateurs apportent une aide précieuse, dont Marthe de la Chevrotière, Louis Geoffroy et Jean Saulnier qui procèdent au montage des éléments pendant le tournage. Au dire de Serge Gagné, il s'agissait «vraiment, pour un film indépendant et son sujet gigantesque, de moyens exceptionnels ${ }^{54} »$. Le montage final, image et son, pour le mixage du film, sera effectué par Jean Gagné.

Sur les lieux, les deux cinéastes s'en remettent surtout à l'improvisation. De pair avec Régis Painchaud (l'interprète d'Edgar), sa conjointe de l'époque Micheline Couture, et Jean-Pierre Masse ${ }^{55}$, ils vont à la rencontre de groupes et de personnes des milieux culturels locaux et sollicitent leur participation au projet de film. Le choix des groupes et des personnes

53. ACPAV, «Historique», www.acpav.ca/acpav/historique (consulté le 5 octobre 2012).

54. Échange courriel avec Serge Gagné, 6 novembre 2012.

55. Comme ils voyageaient en voiture et devançaient l'équipe technique, Régis Painchaud, Micheline Couture et Jean-Pierre Masse tentaient de trouver des participants. Quand l'équipe technique arrivait, le choix se faisait et la rencontre impromptue avait lieu. Échange courriel avec Jean Gagné et Serge Gagné, 6 novembre 2012. 
figurant au montage, tout comme les dialogues, sont entièrement le fruit de l'improvisation. Captées sur le vif, sans grande mise en scène, les entrevues qu'Edgar conduit avec ces gens sont minimalement organisées de façon à préserver ce que l'on considère, chez les frères Gagné, comme l'«authenticité» du témoignage (une caractéristique importante du cinéma direct).

Par ailleurs, cette démarche donne parfois lieu à des scènes d'une grande richesse ethnographique. Comme cette rencontre faite à la fin du tournage avec des habitants du village de Wolf Lake, au nord-ouest de Gatineau. Ces gens passionnés de musique western traditionnelle acceptent alors de s'offrir en spectacle pour eux, donnant lieu à plusieurs courtes prestations musicales, intégrées dans chacune des parties du film.

Quant à la distribution et à la diffusion du film, à partir de 1976, les efforts ont été déployés surtout, et on s'en doute bien, à l'extérieur du circuit commercial. Le Centre d'essai Le Conventum (CEC) - logé à l'ancienne galerie Espace, rue Sanguinet, ancien atelier de décors du Théâtre du Nouveau Monde, devenu ensuite le siège social de l'Association des sculpteurs du Québec - demeure la principale tribune de diffusion de l'œuvre. Fondé en 1974 par André Duchêne, les frères Alain et Régis Painchaud ainsi que les frères Gagné, le CEC se veut le lieu d'une expression commune pour «se rassembler, rejoindre les autres, assurer l'autonomie des moyens de production et la libre circulation des produits culturels québécois ${ }^{56} \%$. On y diffuse des films, des pièces de théâtre, de même que des spectacles musicaux, mais la démarche globale laisse place également à la recherche, aux ateliers et aux expériences de création. Jean et Serge Gagné sont chargés de la gestion du collectif de production cinématographique.

Avec l'aide du Conseil québécois pour la diffusion du cinéma (CQDC) $)^{57}$, Une semaine dans la vie de camarades est aussi diffusé dans le cadre de festivals, journées de cinéma et de séances d'étude un peu partout au Québec. Jean Gagné a lui-même parcouru le Québec pour présenter son film lors de séances de projections privées. Le film voyage également à l'étranger

56. L. Nantel, loc. cit., 125.

57. Organisme à but non lucratif fondé en 1969, financé par le ministère des Affaires culturelles et administré par les professionnels du cinéma. Ses activités comprennent «des lancements en salles commerciales, l'organisation de diverses manifestations (soirées-rencontres au cinéma Outremont, rétrospectives consacrées au cinéma québécois, tournées de diffusion en régions), la promotion des films québécois lors des manifestations cinématographiques et des festivals étrangers, ainsi que la publication de textes...» Voir Michel Houle, "CONSEIL QUÉBÉCOIS POUR LA DIFFUSION DU CINÉMA (CQDC)", dans M. Coulombe et M. Jean, dir., op. cit., 164. 
dans quelques festivals. À la fin des années 1970, la société de production et de distribution à but non lucratif Cinéma libre, fondée en 1976 par André Forcier, Jean Dansereau, Bernard Lalonde et François Brault, l'ajoute à son catalogue. Puisque Cinéma libre dispose de plusieurs circuits de distribution, bien que parallèles et marginau $x^{58}$, le film jouit alors d'une diffusion plus structurée.

Enfin en 1978, à la demande du responsable de l'achat des longs métrages à Radio-Québec (qui devient Télé-Québec en 1996) Daniel Lajeunesse, qui se montre intéressé au film, les frères Gagné acceptent de produire une version écourtée d'Une semaine dans la vie de camarades. Le format de quatre heures, on s'en doute bien, ne convenait pas tellement à la programmation télévisuelle. La volonté du télédiffuseur de présenter leur film retiendra l'attention de Jean Chabot et de René Pothier de l'Institut québécois du cinéma (IQC), qui accepteront de verser une aide à la réalisation pour créer un film de 90 minutes. Après réflexion, les frères Gagné décident plutôt de créer un nouveau film à partir de séquences prises dans la version de 1976. Avec l'aide de Jacques Parent, directeur de la production à l'Office du film du Québec, et le cinéaste Michel Chabot, ils procèdent également au visionnement et à l'échantillonnage de films d'information gouvernementale qui viendront compléter le matériel. L'aventure s'achève en 1980 et le résultat s'intitule: $\dot{A}$ vos risques et périls.

Ses auteurs le décrivent comme une "[m]outure contre-culturelle sur les grands projets qu'on [...] prépare: le stade, le marathon, le jardin botanique, les autoroutes, le festival des films du Monde. Une sommation de plusieurs manœuvres pour éloigner la société du partage et de la libertés9. » Le film prend l'affiche lors de la Semaine du cinéma québécois. Dans la seconde moitié des années 1980, Radio-Québec diffuse ainsi cette "nouvelle version» qui contribue au rayonnement d'Une semaine dans la vie de camarades en lui donnant une seconde vie.

Tout ce contexte de production et de réalisation d'Une semaine dans la vie de camarades confirme la démarche professionnelle marginale et libertaire qui guide alors le travail des frères Gagné. En marge des circuits commerciaux et de l'industrie, ils s'affirment envers et contre les institutions cinématographiques gouvernementales (au cours des années 1970, ils n'hésitent d'ailleurs pas à dénoncer ce qu'ils considèrent comme un contrôle exercé par l'ONF sur la création), sacrifiant succès et popularité

58. Y. Lever, op. cit., 396.

59. Productions Cocagne, «Les films», http://cocagne.org/cocagne.old/cocagne/les_films.htm (consulté le 3 octobre 2012). 
au profit d'une quête d' "authenticité» jugée incompatible avec les exigences, règles et objectifs des institutions gouvernementales de financement du cinéma. En ce sens, cette affirmation contre-institutionnelle est résolument contre-culturelle.

\section{LE TRAVAILLEUR CULTUREL, AGENT RÉVOLUTIONNAIRE}

Au Québec, la décennie 1970 s'amorce par les événements traumatiques d'Octobre 70, dont le choc se fit ressentir aussi dans le milieu du cinéma. Pour le spécialiste de cinéma Gilles Marsolais, nul doute que ces événements «auront joué un rôle déterminant au regard de l'inconscient collectif du peuple québécois et orienté de façon décisive la conduite socio-économique d'un large courant de cette collectivité ${ }^{60}$ ». Certains films s'en inspirent d'ailleurs directement: Les ordres (1974) de Michel Brault, une fiction documentaire construite à partir de témoignages de gens ayant vécu l'emprisonnement et la torture psychologique; ou encore Bingo (1974) de Jean-Claude Lord, une fiction montrant une société en pleine autodestruction, dans laquelle le personnage principal est un jeune révolutionnaire militant engagé au sein d'un groupe terroriste opposé aux entreprises américaines et aux politiciens et trahi par sa propre grand-mère ${ }^{61}$. L'historien Yves Lever relève également que les événements d'Octobre 70 mèneront à une résurgence soudaine de la censure au cinéma, notamment à l'ONF ${ }^{62}$.

L'impact d'Octobre 70 peut aussi être vu comme un accélérateur d'une remise en question profonde de la société québécoise, que l'on voit poindre déjà vers la fin des années 1960. Les historiens Paul-André Linteau, René Durocher, Jean-Claude Robert et le littéraire François Ricard parlent d'une "phase d'éclatement» qui se veut le théâtre de "nombreuses dissensions [témoignant du fait que] les options se diversifient et [que] les débats se radicalisent ${ }^{63}{ }^{m}$. On note l'essor de mouvements nationalistes divergents qui trouvent « une certaine unité ${ }^{64}$ » dans la fusion avec le Parti québécois de René Lévesque en 1969, tout comme la multiplica-

60. Gilles Marsolais, «Michel Brault, cinéaste exemplaire : à propos de son film Les ordres », Vie des Arts, 20, 78 (1975): 44.

61. Voir l'excellente analyse de Bingo par le politologue Christian Poirier dans Le cinéma québécois. À la recherche d'une identité?, tome 1: L'imaginaire filmique (Québec, Presses de l’Université du Québec, 2004), p. 112.

62. Il évoque les cas de trois films: Cap d'espoir (1976) de Jacques Leduc, On est au coton (1976) de Denys Arcand ainsi que 24 heures ou plus (1973) de Gilles Groulx. Voir Yves Lever, Anastasie ou la censure du cinéma au Québec (Québec, Septentrion, 2008), p. 257-263.

63. Paul-André Linteau et al., Histoire du Québec contemporain, tome 2 : Le Québec depuis 1930 (Montréal,

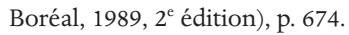

64. Y. Lever, Histoire générale..., op. cit., 241. 
tion des revendications de groupes sociaux marginalisés (les Noirs et les femmes surtout). L'historien Sean Mills affirme qu'au

cours de la deuxième moitié des années 1960, les militants noirs transforment Montréal en un important centre de la pensée noire, où convergent bon nombre des principaux intellectuels noirs du monde, pour discuter avec les militants locaux du contexte mondial de la question de la race et de l'impérialisme $e^{65}$.

Les femmes, tant anglophones que francophones, s'organisent également autour de différentes associations féministes, comme le Montreal Women's Liberation Movement (MWLM) ainsi que le Front de libération des femmes $(\mathrm{FLF})^{66}$. Cela dit, la situation québécoise est en phase avec l'effervescence intellectuelle et révolutionnaire amenée par les événements de Mai 68 en France ainsi que par les mouvements hippies et d'émancipation afro-américaine au sud de la frontière.

La mouvance contre-culturelle québécoise s'inspire de cette vague de contestation et de remise en question de la seconde moitié des années 1960. Et le cinéma, commercial ou pas, n’y échappe guère. Plusieurs films prenant l'affiche au début des années 1970 démontrent justement ce vide ou cette quête identitaire. Pensons à Un pays sans bon sens ou wake up, mes bons amis !!! (1970) de Pierre Perrault, Mon oncle Antoine (1971) de Claude Jutra ou encore La vraie nature de Bernadette (1972) de Gilles Carle. Une semaine dans la vie de camarades, puisqu'il s'intéresse justement à la contreculture et qu'il est produit par des contre-culturistes, prend racine nécessairement dans l'esprit révolutionnaire ambiant et selon une démarche politique qui se manifeste à travers une telle prise de parole au sein de l'espace public.

On retrouve cette image symbolique de la prise de parole au cœur même du récit. Dans son périple à travers les régions du Québec, la présence d'Edgar Azède Plamondon s'efface au profit de celle des artistes qu'il rencontre. Les discussions qu'il entame avec ces travailleurs culturels régionaux visent surtout à leur donner la parole en leur permettant d'investir symboliquement l'espace public et de critiquer les pouvoirs politique et économique. Ce faisant, Edgar agit tel un porte-voix, ce qui ajoute au caractère politique et social du film. On se trouve ainsi en présence

65. Sean Mills, Contester l'empire: pensée postcoloniale et militantisme politique à Montréal, 1963-1972 (Montréal, Hurtubise HMH, 2011), p. 111.

66. Voir le chapitre 5 dans ibid., 141-163. 
d'une variété de discours alternatifs, unifiés par le personnage d'Edgar et dirigés contre l’État.

Dès le générique d'ouverture, les cinéastes affirment leur volonté d'offrir, avec ce film, une forme de contre-discours politisé. Le texte placé en exergue et qui défile au rythme de la musique du groupe Cellule $3^{67}$ est révélateur de cette intention:

Parce que nous croyons qu'il [le film] pourra regrouper une énergie non polluée et/ou polluable, de par ses possibilités d’accélérer une dialectique tendant à casser la stabilité d'une permanence crasse de l'habitude de l'homocivilisens et à créer le pôle de l'imagination au pouvoir ${ }^{68}$.

Et c'est par un portrait visuel et sonore de l'état de la culture québécoise et de la situation des travailleurs culturels qu'ils entendent réaliser cet objectif.

Le choix du terme "travailleur culturel», bien que commun pour l'époque et signifiant l'artiste qui vit de son art, n'est cependant pas anodin. Influencée par l'idéologie marxiste qui circule librement à l'époque au sein de différents milieux, dont ceux de la contre-culture, cette appellation implique une certaine forme d'engagement politique, certes plus idéologique que pratique, mais qui intègre une dimension de contestation et sous-tend une lutte de classes, pour reprendre la phraséologie marxiste. Et c'est bel et bien le travailleur culturel qui intéresse ici les frères Gagné, c'està-dire l'artiste dans son rapport aux pouvoirs politique et économique à l'égard de la culture.

Nombreuses sont les scènes du film qui exemplifient ce parti pris. Edgar interroge le peintre et sculpteur Robert Geoffroy sur son art, son métier et sur l'École-atelier en sculpture du bois de Saint-Jean-Port-Joli où il étudie. Geoffroy ne manque pas de situer la proximité de son art de la situation des travailleurs, critiquant au passage le gouvernement perçu comme une force avilissante à l'égard de ces derniers:

R. Geoffroy: J’ai pas été mis dans un vase clos, une société bin bin fermée, une société des intellectuels. Ça a sûrement influencé sur la sorte de peinture que je fais aussi, d'avoir travaillé avec des travailleurs. Tu regardes, je suis figuratif. Je déforme mes personnages, mais ça reste des bonshommes pis y ont des histoires. Finalement, je fais de la peinture pour conter quelque chose,

67. Michel Perron à la guitare, Maurice Richard à la basse, Charlot Barbeau au piano et Bedet Vaillancourt à la batterie.

68. J. Gagné et S. Gagné, op. cit., $00: 03: 20$ à $00: 03: 43$. 
pis le conter à du monde. Pas nécessairement des intellectuels, ceux qui se tiennent din musées, din galeries.

Edgar: Les ateliers de Saint-Jean-Port-Joli, ça regroupe quoi au juste?

R. Geoffroy: Ceux qui vont suivre ces cours-là, y en a quelques-uns qui veulent devenir producteurs de petits bonshommes de Saint-Jean-Port-Joli, mais la plupart c'est pour passer six ou huit mois payés par le centre de maind'œuvre. Pis y vont se chercher un projet après ou un autre cours du centre de main-d'œuvre. Pis comme ça, tu passes ton temps, tu tues le temps. Payer pour tuer le temps. Pis ça, le gouvernement favorise ça. Quand t'es payé pour tuer le temps, tu gueules pas ${ }^{69}$.

À un autre moment, Edgar prend le traversier Matane-Godbout pour se rendre sur la Côte-Nord. Il visite un centre sociorécréatif et rencontre Jeannot Gagnon, un animateur culturel avec qui il discute du développement économique de la région et de son impact sur la vie culturelle. Pour ensuite subitement aborder les répercussions du Front commun de mai $1972^{70}$ :

Edgar: Comment s'est développé le capitalisme sur la Côte-Nord, ici?

J. Gagnon : Bon. C’est quand même assez récent. Ça remonte à peu près aux environs des années 1950, suite aux découvertes des minerais de fer. [...] Alors là est venue une main-d'œuvre de l'extérieur, de la rive sud pour la plupart, qui s'en venait au klondike.

Edgar: Avec l'arrivée des gens qui viennent de Matane, de Québec et de Montréal aussi, comment on réussit à former une entité culturelle avec tout ça?

J. Gagnon: Les gens sont venus ici en pensant réellement pas y rester longtemps. Les gens venaient ici et pensaient faire un peu d'argent et ensuite repartir chez eux. [...] Parce que les gens s'identifient pas à leur milieu. Pis quand les gens ne s'identifient pas à leur milieu, y a rien à faire. Y a quand même des manifestations culturelles, mais c'est quand même pas typique du milieu.

Edgar: Qu'est-ce que ç’a été Mai 72 ici?

J. Gagnon : En mai 72, l'occupation de la ville. Faut dire qu'ici c'est, à la différence d'ailleurs, y a 75 pour cent de gens syndiqués. [...] Y a eu un mouve-

69. Ibid., $00: 44: 05$ à $00: 45: 45$.

70. En mai 1972, les trois grandes centrales syndicales du Québec faisaient front commun en déclarant une grève généralisée dans le but de revendiquer un salaire minimum de $100 \$$ par semaine pour chacun des 210000 membres qu'elles représentaient. Voir S. Mills, op. cit., 38-244. 
ment spontané. Pis c'est quand même pas une directive des centrales syndicales. [...] Ça, c'est vraiment une notion d'économique. T'as des travailleurs qui finalement, c'est eux qui font vivre les commerçants, à toutes fins pratiques. Alors un moment donné, tu t'essaies d'avoir l'appui de ces gens-là... tu l'as $\operatorname{pas}^{71}$.

L'alliance symbolique et idéologique entre la lutte des ouvriers et celle des travailleurs culturels est telle, dans le discours, qu'on en vient à associer manifestation syndicale et vie culturelle. Travailleurs et artistes partagent une relation de subordination similaire face à une forme de pouvoir: le premier dans son rapport avec son patron, le capital économique; le second dans son rapport à l'État, au pouvoir politique, qui demeure son principal pourvoyeur. D’ailleurs, parmi les séquences de la Rencontre internationale de 1975 qui figurent au montage d'Une semaine dans la vie de camarades se trouvent plusieurs extraits de conférences de Patrick Straram dit «le Bison ravi» - l'une des figures importantes de la contreculture au Québec - , dont la pensée à l'égard de la culture, politique et politisée, intègre alors pleinement l'idéologie et la rhétorique marxistes. Selon le chercheur Sylvano Santini, Straram

désirait poursuivre avec ses militants la lutte idéologique contre le capitalisme et la bourgeoisie en signant des articles qui dénonçaient les productions culturelles maintenant en place les structures de domination. On s'appliquait à révéler la dimension contre-révolutionnaire, fasciste, petite-bourgeoise des œuvres artistiques [...] et des discours orientés sur des questions qui touchent à la culture au sens non artistique du terme (l'éducation, la langue, la liberté d'expression, le mode de vie, etc. $)^{72}$.

Il faut préciser par ailleurs que les frères Gagné étaient de proches amis de Patrick Straram. "Ce n'était pas notre gourou, mais tout comme», confie Serge Gagné ${ }^{73}$. Jean Gagné l'avait d'abord rencontré en 1972 et 1973 au Château Gatineau dans le cadre de visionnements de films. Ils se côtoyèrent ensuite à la Taverne Wilson, rue Laurier à l'angle de l'avenue du Parc à Montréal. Straram avait l'habitude de l'endroit, tout comme d'autres figures de la contre-culture. Puisqu'ils partageaient une certaine conception de l'idéal libertaire, ils s'étaient rapidement forgé des liens d'amitié. Tant et si bien qu'on peut voir Straram dans d'autres films des frères Gagné, dont L' ou 'L (1973) et La couleur encerclée (1984). 
Au début de la troisième partie du film (intitulée «Contrepoint 3 »), les cinéastes rapportent un discours prononcé par Patrick Straram le mercredi 23 avril, lors duquel il énonce justement les parallèles idéologiques entre le marxisme et la démarche contre-culturelle:

P. Straram: Personnellement, je suis beaucoup plus proche d'un homme comme Vladimir Maïakovski ${ }^{74}$, qui a tenté le jeu de l'individu, mais dans la lutte des classes. Je crois que tout demeure un problème de lutte des classes, d'abord. C'est pourquoi ma position, ce soir, est un peu bizarre, un peu ambiguë. Néanmoins, je pense qu'il était important qu'on sache que ce qui était intéressant dans une démarche contre-culturelle, si vous tenez au mot, c'est sa relation à la lutte des classes ${ }^{75}$.

Straram est certainement l'une des figures contre-culturelles les plus engagées et politisées au Québec. Or, il n’est pas le représentant d’un mouvement organisé, structuré. Il apporte sa voix au chapitre, mais plusieurs ne partagent pas son approche. Une semaine dans la vie de camarades le démontre bien. Pensons notamment à cette scène où Edgar s'entretient avec le cinéaste Jean Dansereau et dans laquelle on retrouve, cette fois, une différence fondamentale entre le travailleur et le travailleur culturel:

Edgar: Est-ce qu'il y a véritablement une différence entre un travailleur de la construction et un travailleur culturel: un travailleur de la sculpture, un travailleur du cinéma?

J. Dansereau: Oui, il y a une différence fondamentale entre les deux travailleurs. C'est que le travailleur de la construction, il peut s'intégrer dans le système des grandes corporations, alors que le créateur du cinéma ne peut pas. À moins de perdre son identité de cinéaste ${ }^{76}$.

Alors que le concept de travailleur culturel permet de mettre en scène la mouvance contre-culturelle québécoise dans une perspective politique et sociale de contre-discours, les représentations du concept d'identité montrent à la fois les différentes incarnations de la contre-culture et l'hétérogénéité des influences et valeurs qui sous-tendent la mouvance.

74. Artiste pluridisciplinaire, grand poète et théoricien, Vladimir Maïakobski est né en Géorgie en 1893. Très jeune, il déménage à Moscou et adhère au Parti social démocrate russe. Il participe notamment à la Révolution bolchévique de 1905. Il amorce sa carrière littéraire à l'âge de 18 ans et devient vite une figure importante de l'école futuriste. Il meurt à Moscou en 1930 après s'être tiré une balle dans le cœur en jouant à la roulette russe. Voir Claude Frioux, «Maïakovski Vladimir Vladimirovitch (1893-1930)», Encyclopédie Universalis [en ligne], www.universalis.fr/encyclopedie/vladimir-vladimirovitch-maiakovski.

75. J. Gagné et $S$. Gagné, op. cit., $01: 17: 23$ à $01: 18: 13$.

76. Ibid., $02: 19: 56$ à $02: 20: 31$. 


\section{LA CULTURE... AU PLURIEL}

Dans son ouvrage Politique et contre-culture publié en 1979, le politologue Gaétan Rochon tente de dégager une définition opératoire de ce qu'est la contre-culture. Il souligne avec justesse que «la contre-culture n'a pas ou a peu analysé sa propre situation, car elle est un mouvement émotionnel plus que rationnel. Elle s'adresse à elle-même. Ce qu'elle vit et ressent est exprimé par l'image évocatrice plutôt que par le concept scientifique ${ }^{77}$.» On ne peut effectivement pas saisir la mouvance contre-culturelle dans son ensemble sans prendre en considération son aspect éminemment émotionnel, vécu plus que réfléchi. «Multiple et contradictoire, poursuit-il, elle n’a jamais été une réalité cohérente. On cherche en vain un manifeste unitaire, une plate-forme commune à toute la contre-culture. Elle est encore un syncrétisme, hétéroclite, peut-être une synthèse en devenir ${ }^{78}$.» C'est d'ailleurs pourquoi le film constitue un médium certainement approprié pour expliquer, sinon représenter, la contre-culture et en faire ressortir ses caractéristiques dominantes, pour comprendre ce que fut l'identité contreculturelle. En se référant à la théorie du «capital culturel» développée par le sociologue français Pierre Bourdieu dans les années 1960 et 1970, laquelle envisage la culture en tant qu'instrument de pouvoir pour l'individu ${ }^{79}$, il convient d'avancer l'hypothèse que la contre-culture, dans sa critique qu' elle formule à l'endroit du pouvoir, s'avère, par extension, une critique de la culture telle qu'elle est instrumentalisée par ce pouvoir.

Une semaine dans la vie de camarades demeure un cas de figure intéressant pour comprendre et analyser ce que la mouvance contre-culturelle définit et perçoit comme étant la culture ou une manifestation culturelle. À la suite du visionnement du film, on réalise qu'il convient davantage de parler de formes plurielles de contre-cultures. Serge Gagné s’identifie, lui, à un courant contre-culturel urbain ${ }^{80}$, par opposition à un courant plus terrien dans lequel la recherche de la liberté passe par un contact privilégié avec la nature, plus près idéologiquement du mouvement hippie américain. Mais voilà deux courants parmi d'autres. En définitive, cette revendication d'une pluralité culturelle se fait néanmoins toujours à l'encontre du pouvoir, ce qui lui confère une dimension politique certaine.

77. G. Rochon, op. cit., 18.

78. Ibid., 18.

79. Voir, entre autres, Pierre Bourdieu, «L'école conservatrice. Les inégalités devant l'école et devant la culture», Revue française de sociologie, 7, 3 (1966): 325-347; et Pierre Bourdieu, "Classement, déclassement, reclassement", Actes de la recherche en sciences sociales, 24, 1978, 2-22.

80. Entrevue téléphonique avec Serge Gagné, 28 octobre 2012. 
Dans cette scène, Edgar discute avec Pierre Léger dit Pierrot-le-fou, artiste pluridisciplinaire (poète, musicien, écrivain) et journaliste. Figure bien en vue de la contre-culture dans les années 1970, Léger a été attaché de presse du ministre de l'Éducation dans les années 1960 et membre du Conseil général du Rassemblement pour l'indépendance nationale (RIN). Il est également membre cofondateur du mythique groupe rock La Sainte Trinité (1970-1972) qui regroupait aussi Plume Latraverse et Pierre Landry. Pierrot-le-fou explique ce que constitue, pour lui, la culture au regard de son métier de journaliste et d'artiste:

Edgar: J'aimerais ça que tu continues à élaborer sur la fonction de journalisme parce que tu y attaches une attention particulière.

P. Léger: Oui, mais ça a été mon premier métier. Celui que j'exerce de temps en temps et que j'aime bin. S't'une gang de fou le journalisme, le monde a du fun là-dedans. On joue. À La Presse, j'me promène autant dans la section «Spectacles» ou «Vie et Culture» que «Sports». Les gars comprennent pu rien. $[\ldots]$ «Nous autres, on pensait que tu t'en tiendrais uniquement à la culture, mais qu'est-ce que tu fais dans le sport?» Bin je dis c'est une forme de culture tabarnak le sport. Le culturel, au sens très large, c'est quoi? C'est toutes les formes d'activité de la vie intérieure chez l'homme. [...]

Edgar: Un sujet un peu plus délicat: pourquoi t'es pas de la Rencontre internationale?

P. Léger: [...] C'est un enchaînement de circonstances. [...] Dans cet esprit-là, je pense qu'on a réussi à monter de quoi d'assez le fun avec des textes nouveaux, des monologues moqueurs sur les mille et un visages de la gauche québécoise ou sur les trop nombreux jeux de force qui s'opposent à l'intérieur de la gauche québécoise. Moi, j'ai jamais vu une gauche aussi divisée que ça tabarnak. Ce qui fait le beau jeu de la droite. Eux autres se tiennent tous. [...] Je me considère socialiste. Au niveau où il faut étatiser toutes les entreprises qui sont issues des richesses naturelles d'un pays. [...] Le partage égal des revenus sacrament ${ }^{81}$.

Si culture et politique ne font qu'un dans son identité d'artiste et de journaliste, on comprend des propos de Pierre Léger qu'il adhère à un courant contre-culturel beaucoup plus engagé.

D'un autre côté, vers la moitié du film, Edgar s'entretient cette fois avec Jean-Gauguet Larouche, sculpteur, poète et cinéaste originaire de La Malbaie dans Charlevoix, spécialiste de la sculpture en fer. Revenu s'établir 
dans sa région natale après une année passée à Paris, Jean-Gauguet Larouche témoigne de son identité de travailleur culturel:

J. Gauguet-Larouche: Quand ma mère m'a appris qui avait une cabane à vendre ici, j'étais à Paris. Pour 350 piastres, elle m'a dit, tu peux acheter une maison. J'ai dit OK, achète-la. Si un jour je suis mal pris, je m'en irai. [...] Y a des castors ici qui font leur cabane. Les oiseaux font leur nid. Pis nous autres osti, on a de la misère à se faire une place.

Edgar: C'est partout pareil. [...] Partout, le monde demande à peu près la même chose. Capable de s'installer. Capable d'avoir un coin.

J. Gauguet-Larouche: Capable de travailler. Parce que tout le monde a droit au travail, sacrament, pis on est réduit... on est pu capable de travailler. C'est écœurant. [...]

J. Gauguet-Larouche: Quand je suis rentré d'Europe, y a des gens qui pensaient que j'allais rentrer avec un accent français. [...] Chu rentré en criss pis en calvaire. Quand tu rentres pis y a rien qui t'attend. Si y a quelque chose qui t'attend, tu te fais canceller pour des raisons politiques, t'aimes moins ça. $[\ldots]$ Faut que tu craches à terre, tu te craches din mains, tu prends ta hache pis tu pioches. Piocher ici, c'est pas plus difficile ${ }^{82}$.

Tout comme chez Pierrot-le-fou, le rapport de la culture à l'identité, chez Jean Gauguet-Larouche, est tout à fait évident. Il s'agit d'un mode de vie qui prend forme dans la pluridisciplinarité artistique engagée pour l'un, et dans la volonté rationnelle de s'affirmer et de se réaliser à travers le travail pour l'autre. Deux visions contre-culturelles distinctes, mais dirigées toutes deux à l'endroit du pouvoir. Un dernier exemple, intellectuel celui-là, du professeur d'histoire Jean Billard - qu'Edgar rencontre en marge de la Rencontre internationale de la contre-culture - , pour qui le sens de l'histoire et ses effets sur la culture critique demeurent une arme identitaire puissante pour contrer le contrôle du politique sur l'individu:

J. Billard : Il est bien évident qu'on ne peut pas le percevoir [ce courant contreculturel] autrement que d'une façon historique. L'ennui est précisément de voir que ce phénomène historique essaie d'échapper le plus possible à l'histoire. Ses propres thèses, si tu veux, essaient de nous faire croire que l'histoire est dépassée. Or, précisément, c'est ça pour moi le danger majeur d'une telle position. C'est qu'elle ne fait que corroborer, si tu veux, les instances du pouvoir qui tentent, par tous les moyens justement, de désamorcer l'histoire dans l'esprit des jeunes, qui participent aussi bien d'ailleurs à cette semaine 
que ceux que j'ai l'occasion de rencontrer dans mes cours, qui sont des cours de cégep. Et on s'aperçoit que les jeunes sont totalement déphasés. Ils n’ont plus conscience d'une histoire qui remonte ne serait-ce qu'à deux ans, trois ans. 1970 pour eux, j'ai l'impression de leur parler de Jeanne d'Arc. Et que c'est un phénomène extrêmement dangereux dans la mesure où, à la faveur de ce vacuum qui se crée, ce vacuum historique, le fascisme immédiatement se réinsère, revient en force, utilise tous les moyens, tous les médias qui, précisément, sont aux mains du pouvoir et qui récupèrent le vide contre-culturel pour pouvoir justement manipuler encore plus facilement et plus directement l'ensemble d'une population ${ }^{83}$.

Une semaine dans la vie de camarades représente assez bien les multiples courants d'expression qui alimentent la mouvance contre-culturelle dans les années 1970. Différentes, divergentes parfois, ces nombreuses perspectives, qui montrent clairement l'adéquation de la culture à l'identité, concourent cependant toutes à la critique du pouvoir politique et économique. Dans l'ensemble, on dénonce surtout le gouvernement, celui du Québec, et sa conception très homogénéisée et discriminatoire de la culture $^{84}$. Une position qu'endossent également les frères Gagné si l’on en croit cette scène de fiction, au milieu du film, dans laquelle Edgar entre par effraction dans un immeuble du ministère des Affaires culturelles du Québec pour scruter les dossiers de subventions.

Mais au-delà de la simple critique du pouvoir, le film propose également une piste de solution. La libération individuelle de l'artiste, ou du travailleur culturel, pourrait passer par la lutte collective et nationale visant à faire du Québec un État souverain.

\section{LA LIBÉRATION INDIVIDUELLE PAR LA LUTTE COLLECTIVE}

Dans Une semaine dans la vie de camarades, la quête de l'identité et de la liberté individuelle passe par un projet politique et identitaire, celui de la “libération» du Québec (pour reprendre l'expression de l'époque). Contexte oblige, le film est réalisé à la veille de la prise du pouvoir par le Parti québécois de René Lévesque en 1976. Fondé en 1968, le Parti québécois avait su rallier déjà plusieurs groupes nationalistes divergents pour un bien commun. Si la dénonciation du pouvoir en place et de ses institutions demeure une caractéristique importante de la contre-culture québécoise, sans doute était-il prescrit que le projet d’indépendance natio-

83. J. Gagné et S. Gagné, op. cit., $01: 18: 50$ à $01: 20: 58$.

84. Cela dit, la critique de la culture «canadienne» n'est pas absente des préoccupations de certains acteurs de la contre-culture. 
nale du Québec devienne un objectif partagé par plusieurs protagonistes de la mouvance, à tout le moins les plus engagés.

Cette idée d'une liberté individuelle qui passe par l'affirmation nationale trouve des échos à quelques endroits dans le film ${ }^{85}$, comme dans cette rencontre entre Edgar et le sculpteur et peintre Armand Vaillancourt, à son atelier:

A. Vaillancourt: Je vois une lueur. Je pense, depuis trois mois, y a réellement une espèce de dépression collective face à la situation politique au Québec. Je trouve qu'il y a beaucoup trop de monde qui déferle et les efforts que chacun des individus, ou des groupes, qui sont faits actuellement, je trouve c'est malheureux que ce soit perdu pis que c'est presque à recommencer continuellement. Moi je trouve ça bin irritant et bin épuisant de voir qu'on peut pas s'atteler davantage, qu'il y ait pas plus de solidarité entre les groupes, les individus, pour une cause commune. [...] On a un pays à libérer. On sait qu'il y a des choses à faire. On a un territoire qui nous appartient pas, c'est un territoire occupé. On a l'industrie, le commerce, tout ce qui nous entoure, toutes les corporations multinationales qui viennent envahir notre pays et il faut se débarrasser de ça. [...] Je pense que sacrifier une partie de ta vie, quand t’as vécu un bout de temps, pour la libération du Québec, je pense que ça vaut la peine ${ }^{86}$.

On comprend dans cet extrait toute la difficulté de concertation dans un mouvement à l'intérieur duquel la quête de l'individualisme prime sur l'organisation collective. En témoigne notamment un autre exemple, celui-là tiré d'un groupe de motards du Saguenay, les O Conquatcheros, qu'Edgar rencontre dans le stationnement d'un garage:

Edgar: C'est quoi le club comme ça? C'est une famille? [...] Non, mais c'est quoi que ça prend dans ta vie?

Crapo: Qu'est-ce que ça prend dans ma vie, m'a te le dire. Ça prend ma vie au complet. [...] Notre club pour moi, c'est pas comme une famille. Comment je pourrais bin te dire ça. J'ai pas été longtemps à l'école. J'ai été jusqu'à la neuvième. Non mais y a pas de mot pour définir ça. Ça, un club de même, c'est gros pour moi. [...]

Edgar: Mais là vous vivez au Saguenay, au Lac-Saint-Jean, une grosse région qui est dominée par l'Alcan [...] C'est une toute-puissance qui contrôle tout, les médias, l'information.

85. Cela dit, cette finalité plus politique n’est pas partagée par tous les tenants de la contre-culture québécoise. Pour certains, Jean Basile notamment, les frontières géopolitiques n’ont pas de véritable valeur. La liberté passe plutôt par le développement d'une conscience universelle.

86. J. Gagné et S. Gagné, op. cit., $02: 15: 18$ à $02: 17: 20$. 
Crapo: Non, mais c'est vrai qui contrôlent pas mal tout ici, mais pas moi. Moi, y me contrôleront jamais. [...]

Edgar: Mais qu'est-ce que ça prendrait au niveau d'un Québec pour changer les choses?

Crapo: Ah! Un pays libre mon petit ${ }^{87}$ !

Pour «Crapo» (surnom d'un des motards), il ne fait nul doute que le renversement du contrôle économique, détenu alors dans la région du Saguenay par la compagnie Alcan, ne peut se réaliser que par l'indépendance nationale. Il y a là une association directe entre pouvoir politique et pouvoir économique.

Avant le générique de fin, un plan large montre le Parlement d'Ottawa, devant lequel sont assemblés plusieurs manifestants. La scène, intitulée "La patrie des drapeaux», est accompagnée d’un monologue bien senti de Pierre Léger, tiré de son livre Embarke mon amour, c'est pas une joke, accompagné par la musique du groupe la Gang du Kébek ${ }^{88}$. Le constat est clair: le projet d'indépendance nationale est perçu comme la solution à tous les maux. Or, l'alliance entre contre-culture et nationalisme pose plusieurs problèmes fondamentaux. Selon Gaétan Rochon,

à cause de la présence du fait nationalitaire, la contre-culture québécoise est coincée entre l’Égo et le Nous. Elle ne peut ignorer la dimension nationale, mais sa dominante de libération individuelle tend à l'estomper; la délivrance des esprits et des corps demeure au premier rang de ses préoccupations ${ }^{89}$.

Si le projet d'un Québec indépendant se voit présenté dans le film en tant que piste de solution à la quête identitaire des contre-culturistes, Serge Gagné n’hésite pas à préciser qu'il s'agissait uniquement, pour son frère Jean et lui, d'un pas dans la bonne direction sans être une finalité en soi. Il convient également de préciser que cette proposition n’a jamais été l'objectif commun de tous les contre-culturistes ${ }^{90}$.

\section{CONCLUSION}

«Nous refusons la domination culturelle d'un peuple par une minorité ${ }^{11}$. » Cette citation plaquée à l'écran à la toute fin d'Une semaine dans la vie de camarades résume bien le propos de la présente démonstration. Assertion 
politique forte et engagée (le verbe "refuser»), elle montre comment la mouvance contre-culturelle fut surtout une prise de parole dirigée à l'endroit d'un pouvoir, ici politique et économique. La quête d'Edgar Azède Plamondon dans le film, son périple à travers les régions du Québec, vise à donner une voix aux travailleurs culturels et à leur permettre de dénoncer une relation de pouvoir (entre "un peuple» et "une minorité») dans une perspective de subordination («la domination»... «par»...). La citation ne manque pas non plus de statuer sur cette revendication dite collective (le "nous»). Dans le film, le sculpteur André Fournelle le confirme: «Disons qu'on se regroupe quand ça va mal ${ }^{92}$.»

En dépit de courants divergents qui l'alimentent, la contre-culture se veut tout de même une mouvance, c'est-à-dire une force qui induit un mouvement dans une direction, sans que le but ou l'objectif soit unique ou partagé. L'essence de la contre-culture réside précisément dans cette agitation et moins dans un ou des résultats escomptés. Le politologue Gaétan Rochon parle d'un "élan vital, [d'un] désir de l'expérience concrète, $[\mathrm{du}]$ maintien de l'individualisme en même temps que [d'une] recherche de liens communautaires, [d'un] refus du système, de ses valeurs officielles, de l'intégration culturelle ou ethnique ${ }^{93} \ldots$ ”

Une semaine dans la vie de camarades nous renseigne également sur la conception plurielle de la culture par les tenants de la contre-culture au Québec. Ces cultures se manifestent autant à travers le western traditionnel des habitants de Wolf Lake, le club de motards O Conquatcheros au Saguenay, les cours d'histoire de Jean Billard et de Léandre Bergeron, le cinéma expérimental et marginal de Johnny Fecteau (on voit quelques scènes de son premier film, L'île aux bijoux), la musique de Plume Latraverse et Serge Chapleau, les sculptures d'Armand Vaillancourt et celles de Jean-Gauguet Larouche, les séances de mantra d'Allen Ginsberg, les chroniques de sport de Pierrot-le-fou, la poésie de Josée Yvon, les discours de William S. Burroughs, les chansons de Ti-Loup de Percé, etc. La citation rappelle également que la mouvance contre-culturelle demeure un combat identitaire («la domination culturelle d'un peuple»). En ce sens, le film des frères Gagné constitue ainsi un vibrant plaidoyer pour un contre-pouvoir.

Une semaine dans la vie de camarades est un document cinématographique qui comporte une dimension sociologique et historique à la fois riche et 
complexe sur la mouvance contre-culturelle dans ses rapports à la notion de pouvoir. Il nous renseigne à la fois sur les caractéristiques et enjeux d'un courant cinématographique (les frères Gagné étant, tous deux, des contre-culturistes de la première heure) de même que sur l'imaginaire contre-culturel. 